\title{
Improved Cropland Mapping in Ethiopia
}

\author{
Christoph PERGER ${ }^{1}$, Ian MCCALLUM ${ }^{1}$, Franziska ALBRECHT ${ }^{1}$, Linda SEE ${ }^{1}$, \\ Steffen FRITZ ${ }^{1}$ and David THAU ${ }^{2}$ \\ ${ }^{1}$ IIASA, Laxenburg/Austria·pergerch@iiasa.ac.at \\ ${ }^{2}$ Google, Mountain View/CA/USA
}

This contribution was double-blind reviewed as extended abstract.

\begin{abstract}
Across the globe, accurate national spatial datasets on cropland extent are lacking. These are necessary for a number of reasons, including accurately monitoring and predicting crop yield, land use, land acquisitions and food security. This study describes the use of crowdsourcing information retrieved over Ethiopia depicting the extent of cropland area. This information has been used to train a classification algorithm in Google Earth Engine to produce a continuous cropland extent map of Ethiopia. Preliminary results of this novel approach are encouraging, with an overall validity of $96 \%$.
\end{abstract}

\section{Introduction}

In particular in Ethiopia, large disagreement occurs among existing publically available cropland maps (FRITZ et al. 2011). This is due in part to a lack of credible in-situ data, so called training points, which could be used to train image classifiers. Thus a crowdsourcing exercise (based upon the Geo-Wiki platform) would help us to make a major step forward in being able to better understand in which areas crops are actively cultivated. One reason for concern is that large scale acquisition or leasing of lands in developing countries (e.g. Ethiopia) for purposes such as biofuel production is on the rise (ABBINK 2011, RAHMATO 2011). Eastern Africa and Ethiopia in particular are one of the most targeted areas over the globe in terms of land deals (RULLI et al. 2013, LAND MATRIX PARTNERSHIP 2013). Land acquisitions could impact existing agriculture (and hence food security (LIU et al. 2008)) and could potentially lead to the displacement of the local population. Armed with an improved set of in-situ data, we are much better positioned to train image classifiers to produce improved cropland maps. In an effort to find a scalable solution, we turned to Google Earth Engine (GEE; http://earthengine.google.org), which contains an ever expanding set of global imagery, image classifiers, and the ability to ingest training points. With the potential to perform this procedure over any region across the globe the GEE offers a very timely methodology.

\section{Data Acquisition}

In a nutshell, Geo-Wiki.org is a crowd-sourcing tool used to collect information based on satellite and aerial imagery (FRITZ et al. 2012, PERGER et al. 2012). We hosted a campaign 
(referred to as a hackathon) to rapidly collect data as part of the international initiative RHOK (Random Hacks of Kindness - Hacking for Hunger), organized by USAID (U.S. agency for international development) in October 2012. Registered users were guided to pixels of $1 \mathrm{~km}^{2}$ and were asked to identify the presence of cultivated land and settlements in samples taken from Ethiopia, along with their confidence in doing so. The Geo-Wiki is based on the Google Earth browser plug-in overlaid with the pixel outline of the samples generated in the PostgreSQL/PostGIS database. User feedback is collected using a simple user interface, requesting the user to indicate high, medium, low, or no presence of cultivated land and settlements inside the pixels. In addition, the user has to indicate certainty over the selected options. After submitting the selected options the system automatically guides the user to the next sample pixel to repeat the actions. The system was designed such that at least two volunteers were sent to the same location, in order to increase confidence in the provided information. Figure 1 shows a screenshot of the GeoWiki user interface for a sample pixel in Ethiopia.

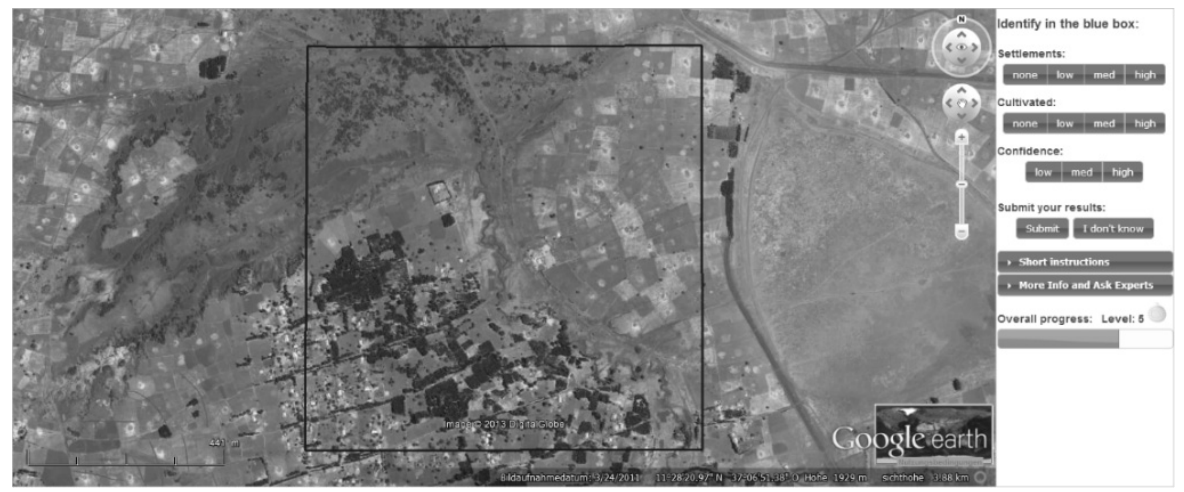

Fig. 1: Geo-Wiki hackathon user interface

During the hackathon weekend, more than 2000 sample points were submitted by the users. The Geo-Wiki hackathon continued after that weekend for 3 more weeks and gathered approximately $82 \mathrm{~K}$ validations on approximately $30 \mathrm{~K}$ unique locations.

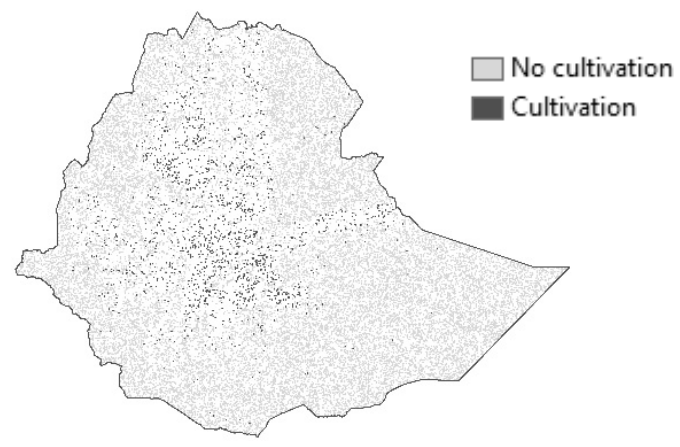

Fig. 2: Hackathon results showing $24 \mathrm{~K}$ locations with agreeing validations 
These are areas where land acquisitions may affect the local population so publishing a better map of cultivation might help to stop these acquisitions in the future, preserve the livelihoods of the local population and improve local food security. Out of those locations, only agreeing validations were used. Figure 2 shows the $24 \mathrm{~K}$ locations with at least two independent and agreeing validations in the cropland domain were submitted without any disagreement by other users.

\section{Methodology}

In order to produce a complete map and to obtain an estimate of the actual area under cultivation using the approximately $30 \mathrm{~K} 1 \mathrm{~km}^{2}$ points, we have several options. These include some form of GIS interpolation methods, or to use our crowd-sourced points to train a classifier with satellite imagery. The GEE provides an online platform for satellite data classification suitable for this task. It provides the tools for such classification and an ever expanding set of satellite data. Furthermore it allows for the ingestion of data for training and validation, which in this study was derived from the Geo-Wiki.

Firstly, we created a subset of points, where cropland was either non-existent or high, and where all data providers agreed on the classification. This reduced the original dataset down to approximately 2000 points. These were loaded into Google Fusion Tables (http://tables.googlelabs.com), and used as training data. The Landsat 7 composite available in the GEE was then used as input data. The Landsat 7 composites available in the GEE are made from Level L1T orthorectified scenes, using the at-sensor radiance. We used the annual composite for the five-year period from 2008-2012. For image classification, we used the Random Forests classifier at $30 \mathrm{~m}$ resolution. The MODIS IGBP layer was used as a water mask.

\section{Results}

The method presented in this study has resulted in the first crowd-sourced cropland map of Ethiopia (figure 3). The resulting map represents an improvement over what is currently available for cropland extent at the national level, particularly in terms of resolution. Several issues still need to be addressed, one important issue being that differences between the timestamp of the Landsat mosaic pixels and the Geo-Wiki training points add confusion to the classifier, particularly crucial in cropland areas. Nonetheless, it would appear that the GEE in combination with the crowd-sourced training points can deliver an improved national cropland map in a fraction of the time that traditional methods require. Furthermore, the methodology present here is scalable, and has the potential to be applied across all regions of the globe where national cropland maps are of poor quality or non-existent.

Evaluation of the methodology presented here could potentially occur using maps derived from interpolation. Additionally, independent crowd-sourcing points could be used to evaluate this product. 


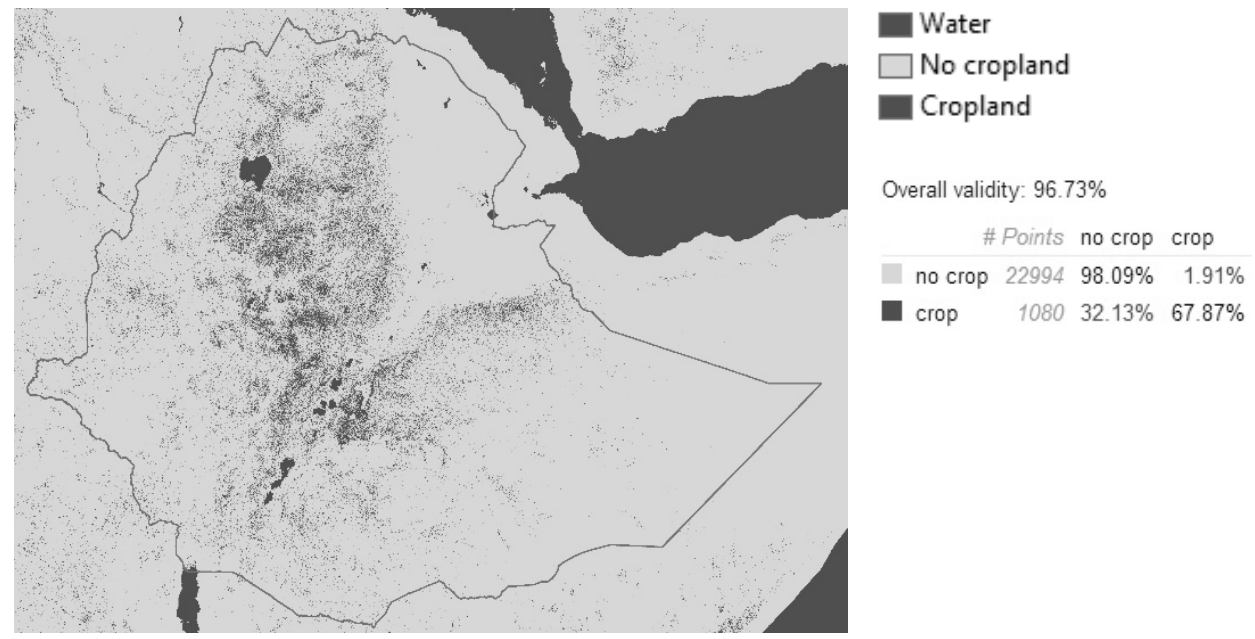

Fig. 3: The resultant cropland map for Ethiopia, with GEE validity report

\section{References}

ABBINK, J. (2011), Land to the foreigners: Economic, legal, and socio-cultural aspects of new land acquisition schemes in Ethiopia. Journal of Contemporary African Studies, 29 (4), 513-535.

Fritz, S., McCallum, I., Schill, C., Perger, C., See, L., Schepaschenko, D., Van Der Velde, M., KraXner, F. \& OBERsteIner, M. (2012), Geo-Wiki: An online platform for improving global land cover. Environmental Modelling \& Software, 31, 110-123.

Fritz, S., You, L., Bun, A., See, L., McCallum, I., Schill, C., Perger, C., Liu, J., HANSEN, M. \& OBersteiner, M. (2011), Cropland for sub-Saharan Africa: A synergistic approach using five land cover data sets, Geophysical Research Letters, 38, L04404.

LAND MATRIX PARTNERSHIP (2013), Land Deals: Ethiopia. Online public database on land deals. http://landportal.info/landmatrix/get-the-detail/by-target-country/ethiopia.

LiU, J., Fritz, S., Van Wesenbeeck, C. F. A., Fuchs, M., You, L., Obersteiner, M. \& YANG, H. (2008), A spatially explicit assessment of current and future hotspots of hunger in sub-Saharan Africa in the context of global change, Global. Planetary Change, 64, 222-235.

Perger, C., Fritz, S., See, L., Schill, C., Van Der Velde, M., McCallum, I. \& OberSTEINER, M. (2012), A campaign to collect volunteered geographic information and land cover and human impact. In: Jekel, T., CAR, A., Strobl, J. \& Griesebner, G. (Eds.), GI_Forum 2012: Geovisualization, Society and Learning. Wichmann, 83-91.

RAHMATO, D. (2011), Land to investors: Large-scale land transfers in Ethiopia. IS Academie: Land Governance for Equitable and Sustainable Development, Addis Ababa. Rulli, M.C., SAVIORI, A. \& D'OdORICO, P. (2013), Global land and water grabbing. PNAS Proceedings of the National Academy of Sciences of the United States of America, $110(3), 892-897$. 